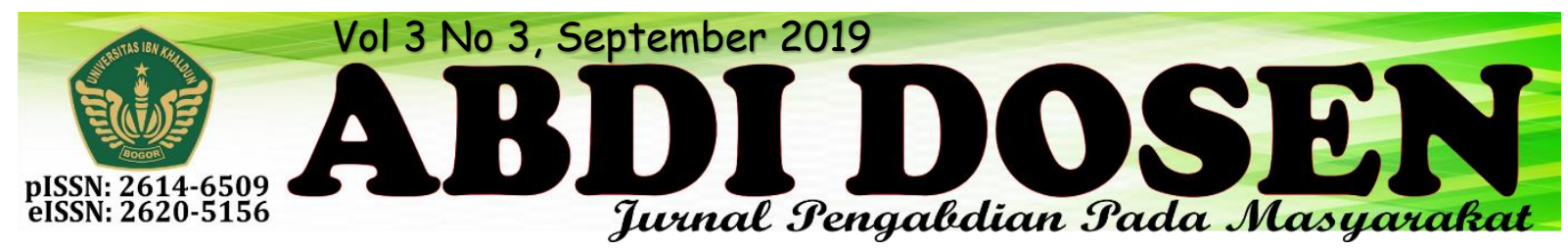

\title{
POS PENGEMBANGAN DAN PEMBERDAYAAN MASYARAKAT (P3M) DESA SUKAMAJU
}

\author{
Alan Jaelani ${ }^{1}$, Fajar Maulidi Rahmani, Ade $\operatorname{Irpan}^{2}$ \\ alan.jaelani@uika-bogor.ac.id \\ Fakultas Keguruan dan Ilmu Pendidikan Universitas Ibn Khaldun ${ }^{1}$, Mahasiswa KKN Kelompok 35 Tahun $2018^{2}$
}

\begin{abstract}
ABSTRAK
Penelitian ini bertujuan untuk mengetahui pembangunan Kabupaten Bogor yang ditujukan untuk semua bidang, tidak terkecuali bidang kesehatan, pendidikan, ekonomi, kelembagaan, dan pemberdayaan lingkungan. Namun demikian, hal tersebut belum mampu dipenuhi oleh pemerintah secara optimal. Universitas Ibn Khaldun Bogor ( UIKA ) sebagai salah satu lembaga pendidikan yang berada di kawasan Kota Bogor memiliki kewajiban untuk berperan secara aktif dalam proses pembangunan tersebut melalui program KKN Tematik Terintegrasi. Metode pengumpulan data yang peneliti gunakan adalah metode survei, Penelitian ini menggunakan metode kualitatif yang disajikan dalam bentuk narasi. Subjek penelitian ini adalah warga desa Sukamaju Kecamatan Cibungbulang, Kabupaten Bogor. Populasi dalam penelitian ini adalah seluruh warga kampung Bubulak RT 02 RW 08. Peneliti telah melaksanakan program bidang Pendidikan, bidang Ekonomi, bidang Teknik, bidang Kesehatan, dan bidang Agama.
\end{abstract}

\section{Kata Kunci : P3M, Pengembangan, Pemberdayaan Masyarakat, Pendidikan}

\section{PENDAHULUAN}

Pembangunan di Indonesia ditujukan untuk semua bidang, tidak terkecuali bidang kesehatan, pendidikan, ekonomi, kelembagaan, dan pemberdayaan lingkungan. Hal ini belum mampu dipenuhi oleh pemerintah secara optimal, dikarenakan kurangnya keikutsertaan fungsi keluarga sebagai pendidikan dasar bagi masing-masing individu. Pembangunan pada lima bidang tadi sangat berpengaruh dalam membangun masyarakat Indonesia. Kesehatan tiap manusia Indonesia menunjang kemajuan bangsa diberbagai bidang. Peran serta dari berbagai pihak sangat dibutuhkan untuk membangun dan mengembangkan kelima bidang tersebut, oleh pihak akademisi termasuk mahasiswa.
Universitas Ibn Khaldun Bogor (UIKA) sebagai salah satu lembaga pendidikan yang berada di kawasan Kota Bogor memiliki kewajiban untuk berperan serta secara aktif dalam pembangunan dibidang kelembagaan, kesehatan, pendidikan, ekonomi serta pemberdayaan lingkungan. Peran tersebut bukan hanya dilakukan oleh mahasiswanya saja, namun oleh masyarakat di sekitar kampus dan masyarakat luas. Salah satu bentuk peran aktif tersebut adalah dengan diadakannya Kuliah Kerja Nyata (KKN) Tematik Terintegrasi yang diselenggarakan oleh Lembaga Penelitian dan Pengabdian Masyarakat (LPPM) UIKA dan dilaksanakan oleh mahasiswa UIKA yang 
bertempat di Desa Sukamaju Kecamatan Cibungbulang Kabupaten Bogor.

Kecamatan Cibungbulang sebagai salah satu kecamatan di Kabupaten Bogor dengan luas wilayah (-+) 3.837,84 $\mathrm{H}$ yang terdiri dari 15 Desa, dengan jumlah penduduk pada tahun 2014 adalah 131.284 Jiwa. Secara demografis memiliki banyak potensi, diantaranya bidang perikanan dan kewirausahaan yang dapat dioptimalkan dalam usaha untuk pembangunan desa serta meningkatkan perekonomian masyarakat desa tersebut. Namun, pada kenyataannya yang diperoleh di lapangan berbagai potensi tersebut selama ini belum dapat dioptimalkan dengan baik oleh masyarakat sekitar. Untuk mendukung hal tersebut, perlu juga dilakukan peningkatan di bidang kesehatan dan pendidikan sebagai dasar terbentuknya sumber daya manusia yang berpotensi agar terciptanya sumber daya masyarakat yang lebih baik.
Desa Sukamaju merupakan bagian dari Kecamatan Cibungbulang dimana Desa Sukamaju memiliki luas wilayah 200 Hektar dan memiliki 9 RW dan beberapa Kampung, khususnya di kampung Bubulak memiliki sektor pertanian yang cukup luas, Kampung Bubulak berada di RW 08. Pelaksanaan Kuliah Kerja Nyata (KKN) Tematik Terintegrasi dinilai karena pembangunan bidang kelembagaan seperti bidang kesehatan, pendidikan, ekonomi serta pemberdayaan lingkungan di kawasan tersebut belum optimal.

Berdasarkan permasalahan di atas, dilaksanakanlah program Kuliah Kerja Nyata Pos Pemberdayaan dan Pengembangan Masyarakat (KKN P3M) Desa Sukamaju Kecamatan Cibungbulang Kabupaten Bogor sebagai salah satu upaya untuk mengoptimalkan fungsi keluarga sebagai anggota masyarakat.

\section{METODE PENGABDIAN}

Tahapan kegiatan dalam pelaksanaan program Kuliah Kerja Nyata terlihat pada bagan dibawah ini

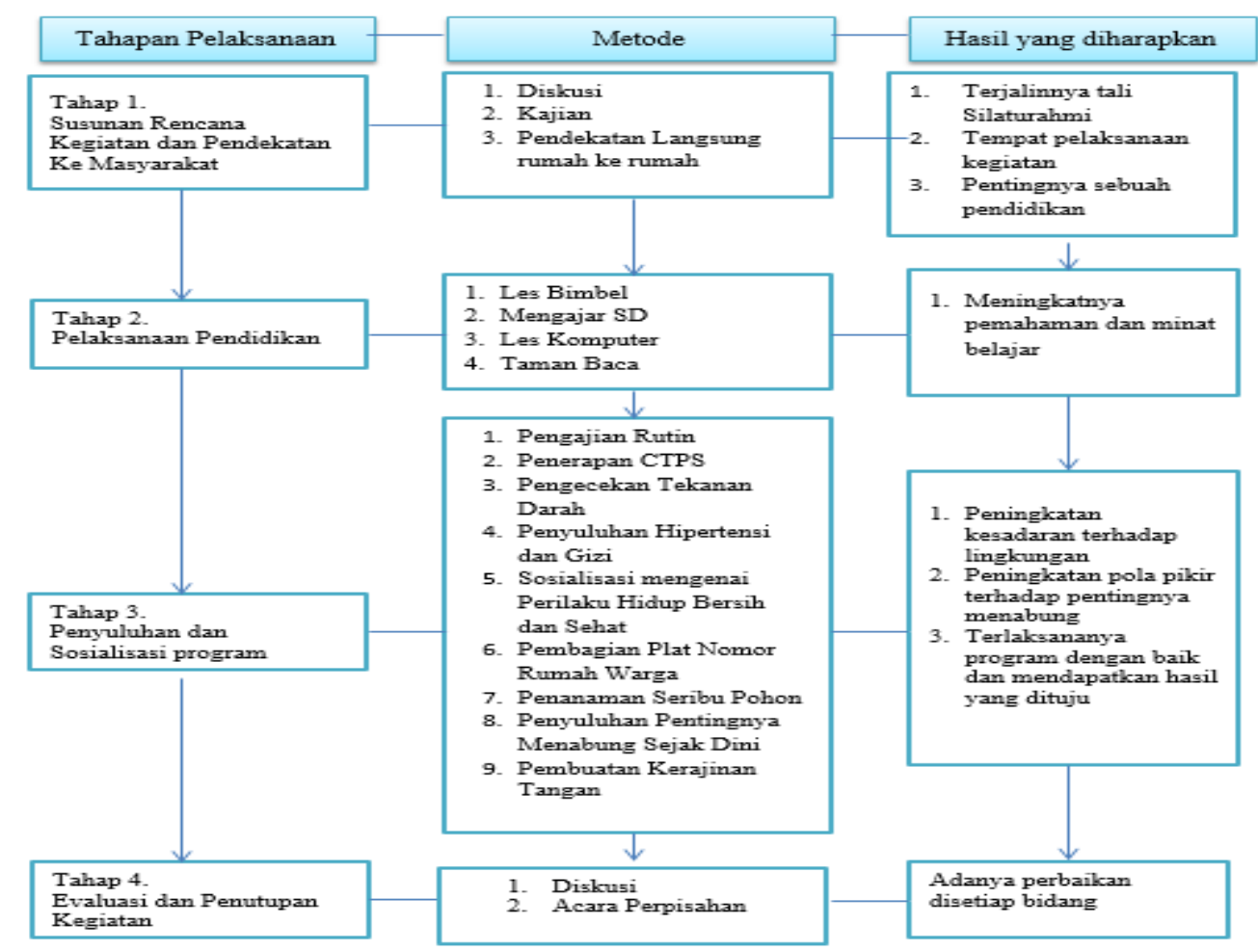


Jadwal Kegiatan

\begin{tabular}{|c|c|c|c|c|c|}
\hline \multirow{2}{*}{ NO } & \multirow{2}{*}{ Kegiatan } & \multicolumn{4}{|c|}{ Minggu } \\
\hline & & 1 & 2 & 3 & 4 \\
\hline 1 & Penyusunan Rencana Kegiatan & & & & \\
\hline 2 & Sosialisasi dan Silaturahmi ke Warga dan Pemuda & & & & \\
\hline 3 & $\begin{array}{l}\text { Menghadiri kegiatan Takbiran dan Sholat 'idul Adha di kampung } \\
\text { Bubulak }\end{array}$ & & & & \\
\hline 4 & Pengambilan Data Kesehatan Ibu dan Anak & & & & \\
\hline 5 & Penyuluhan dan Praktik CTPS & & & & \\
\hline 6 & Cek Tekanan Darah & & & & \\
\hline 7 & Mengajar Les Bimbel & & & & \\
\hline 8 & Mengajar di SD Cemplang 03 & & & & \\
\hline 9 & Menata Perpustakaan & & & & \\
\hline 10 & Membersihkan UKS dan Penyediaan alat P3K & & & & \\
\hline 11 & Menghadiri Majlis Ta'lim Al-Mukhlisin & & & & \\
\hline 12 & Taman Qur'an & & & & \\
\hline 13 & Sosialisasi Gemar Menabung & & & & \\
\hline 14 & Senam Sehat anak-anak dan Jalan Sehat & & & & \\
\hline 15 & Kegiatan 17 Agustus ke 73 di Posko dan di warga & & & & \\
\hline 16 & Gerak Jalan bersama anak SD & & & & \\
\hline 17 & Penanaman Seribu Pohon & & & & \\
\hline 18 & Pendataan Penduduk & & & & \\
\hline 19 & Pemberian Plat Nomor Rumah & & & & \\
\hline 20 & Penyuluhan Hipertensi Lansia dan Gizi & & & & \\
\hline 21 & Kerja Bakti Renovasi Masjid & & & & \\
\hline 22 & $\begin{array}{l}\text { Mengadakan Pelatihan mengenai Microsoft Office (Word, Excel } \\
\text { dan Power Point) }\end{array}$ & & & & \\
\hline 23 & Nobar Film Kemerdekaan & & & & \\
\hline
\end{tabular}

\section{Metode Pendekatan}

Observasi secara umum adalah proses pengamatan dan pencatatan secara sistematis mengenai gejala-gejala yang diteliti. Dapat dikatakan juga bahwa observasi adalah salah satu metode pengumpulan data dengan mengamati atau meninjau secara cermat dan langsung dilokasi penelitian untuk mengetahui secara langsung kondisi yang terjadi untuk membuktikan kebenaran dari sebuah desain penelitian.
Pendekatan-Pendekatan

\section{Masyarakat:}

1. Pendekatan Religi

Dalam metode ini menggunakan metode pendekatan religi dalam pelaksanaan khususnya dibidang pendidikan agama dan umum . Karena di lingkungan tempat $\mathrm{KKN}$ ini menjunjung tinggi nilai-nilai agama, sehingga penyampain materi dalam programprogam dikaitkan dengan religi. Seperti mengajar bimbel berisi hapalan surat dan artinya ,hapalan hadits, doa sehari-hari. 
Serta ikut aktif dalam kerja bakti renovasi masjid. Serta pendekatan kepada remaja melalui diskusi tentang pentingnya pendidikan bagi kehidupan mereka dimasa yang akan datang.

2. Pendekatan Berdasarkan Karakter Masyarakat

Pendekatan berdasarkan karakter masyarakat, yaitu pembinaan yang dilakukan akan sesuai dengan karakter setempat. Sehingga pada pelaksaannya kita memberikan contoh pada masyarakat meskipun pada pelaksanaannya tidak semua berjalan secara lancar tetapi

\section{REALISASI PROGRAM}

Setelah melakukan observasi dan melihat kondisi sarana dan prasarana yang ada di kampung Bubulak maka dari itu program kerja yang telah disusun oleh tim mampu dilaksanakan dengan baik walaupun masih jauh dari kata sempurna. Berikut laporan lengkap tentang pelaksanaan program kerja tim KKN Tematik Terintegrasi Kelompok 35 UIKA Bogor yang terletak di Kampung Bubulak Rt 02 Rw 08 Desa Sukamaju Kecamatan Cibungbulang. Kabupaten Bogor.
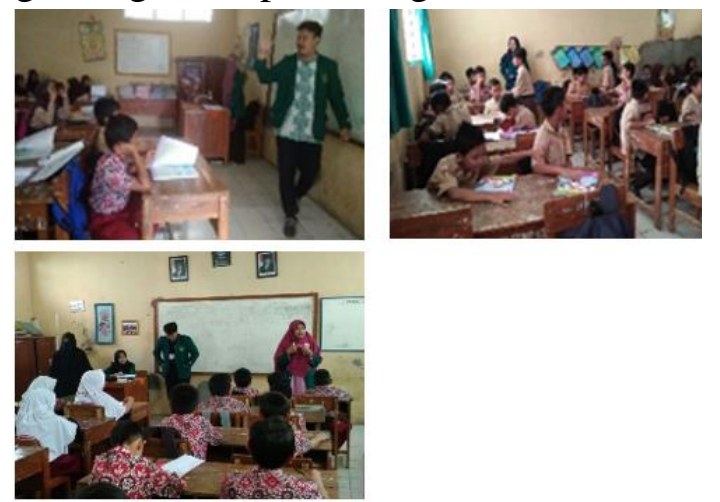

\section{Program Bidang Pendidikan}

a. Dalam bidang pendidikan kegiatannyan membantu mengajar di SDN Cemplang 03 pada hari kamis tanggal 16 Agustus pada kelas 6. Selain itu ka di hari yang sama mengajar pelaajaran agama islam masyarakat sangat antusias setiap program yang terlaksana.

\section{Pendekatan Kekerabatan}

Pendekatan ini berjalan karena adanya kekerabatan dengan masyarakat, dimana mereka menerima kami secara terbuka, khsususnya pada anak-anak dengan mengadakan bimbel. Serta pada para pemuda dengan kegiatan 17 agustus dan kerja bakti.

Penelitian ini dilaksanakan dari tanggal 7 Agustus sampai 7 September 2018. Subjek penelitian ini adalah Desa Sukamaju kampung Bubulak RT 02 RW 08 Kecamatan Cibungbulang Bogor.

dan umum serta Bahasa Inggris, dengan materi Describe Something, dan menghafal kosakata bahasa inggris dengan mudah.

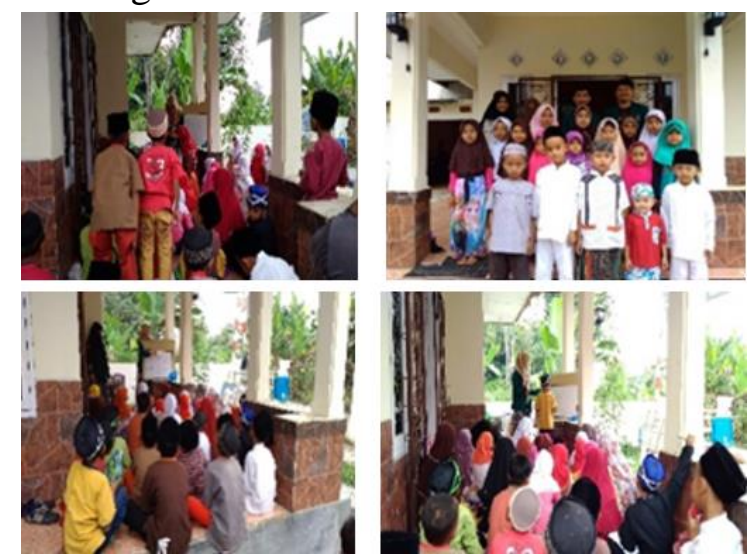

b. Membuka Bimbingan Belajar bahasa Inggris dan pelajaran umum di Posko KKN Kami Pada setiap hari senin-sabtu pada pukul $16.00-17.00$ WIB. 
Bidang Ekonomi

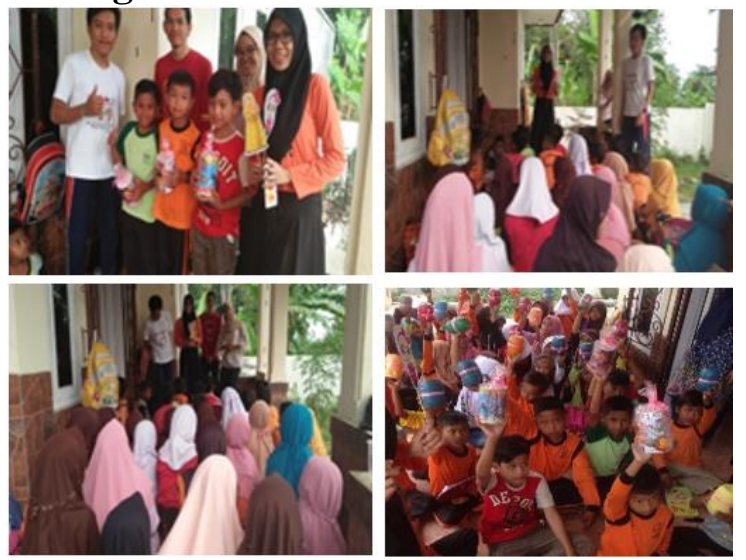

a. Kegiatan sosialisasi gemar menabung pada anak-anak yang ada di lingkungan kampung bubulak RT 02 RW 08 . Penyampaiannya di mengkemas dengan metode bercerita agar mampu dicerna oleh anak- anak

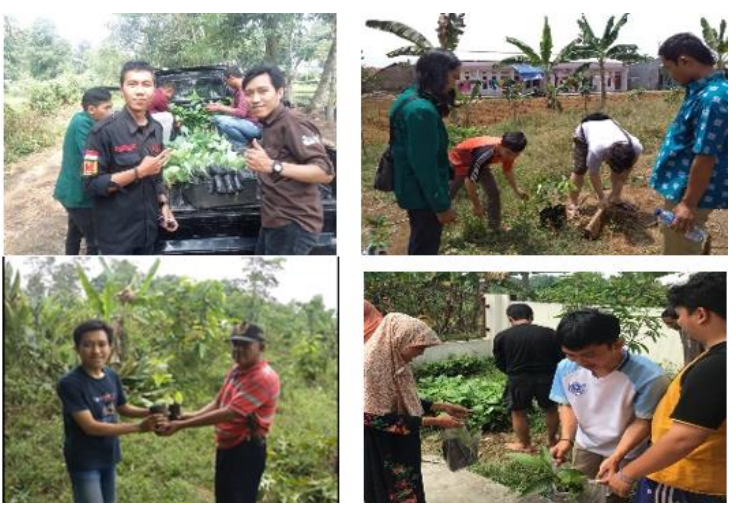

b. Penanaman pembagian Seribu Pohon kepada seluruh masyarakat kampung Bubulak

\section{Bidang Teknik}
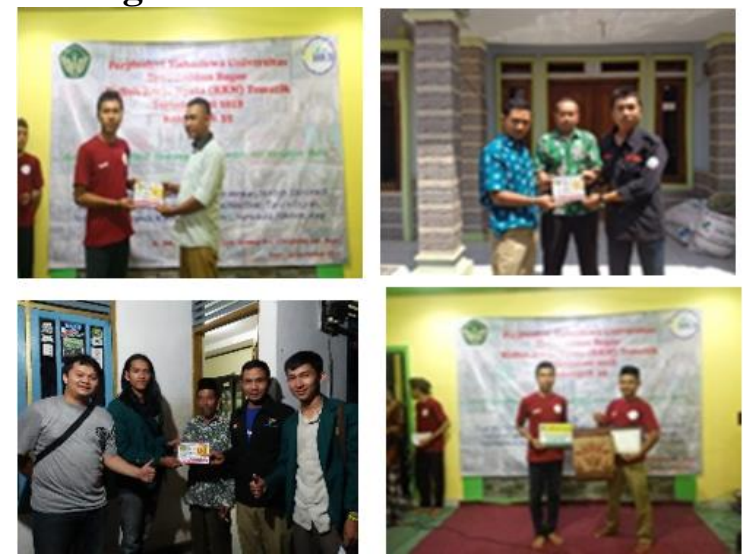

a. Membuat program pengadaan nama Ketua RT, Ketua RW, dan nomor rumah untuk seluruh rumah yang ada di
Kampung Bubulak dengan jumlah 80 buah diibagikan secara gratis

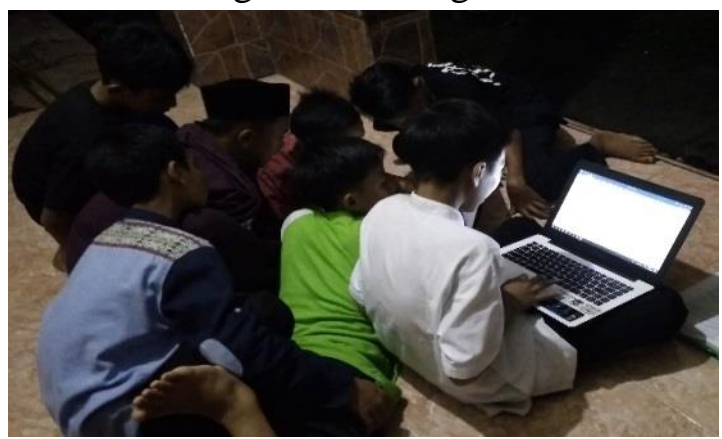

b. Membuka bimbel Pelatihan mengenai Microsoft Office (Word, Excel dan Power Point) pada remaja kampung Bubulak. Dilaksanakan tersebut dilaksanakan pada pukul 16:00- 17: 00 WIB dan pada Pukul 20:00 - 21 - 00 WIB

\section{Bidang Kesehatan}
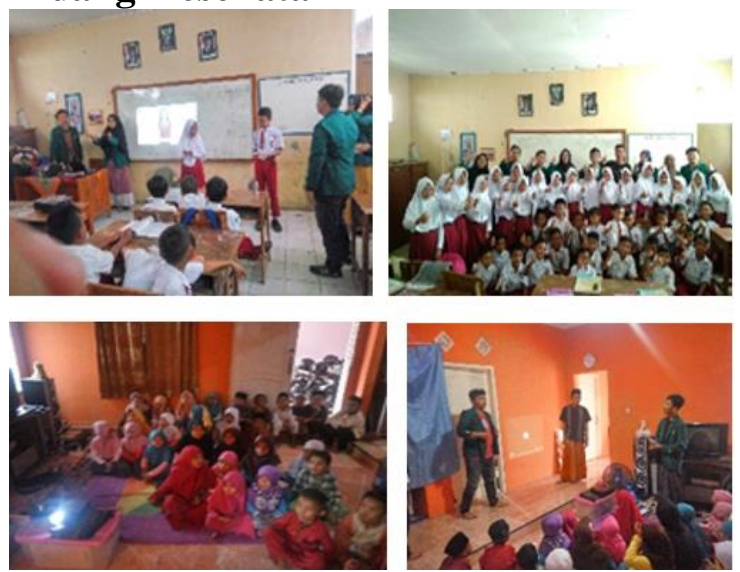

a. Penyuluhan dan Praktik CTPS, Pada kegiatan sebelum praktek CTPS di adakan matrei tentang bahaya kuman. Dan ditutup dengan praktek 6 langkah cuci tangan . 


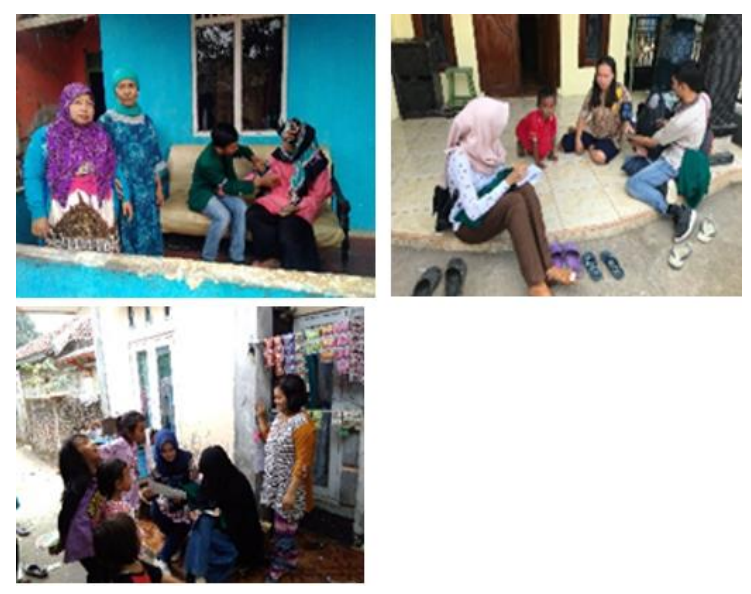

b. Program cek tensi darah pada masyarakat kp. Bubulak. program ini bertujuan untuk mengetahui tekanan darah pada masyarakat kp. Bubulak khsususnya pada bapak-bapak dan ibuibu.
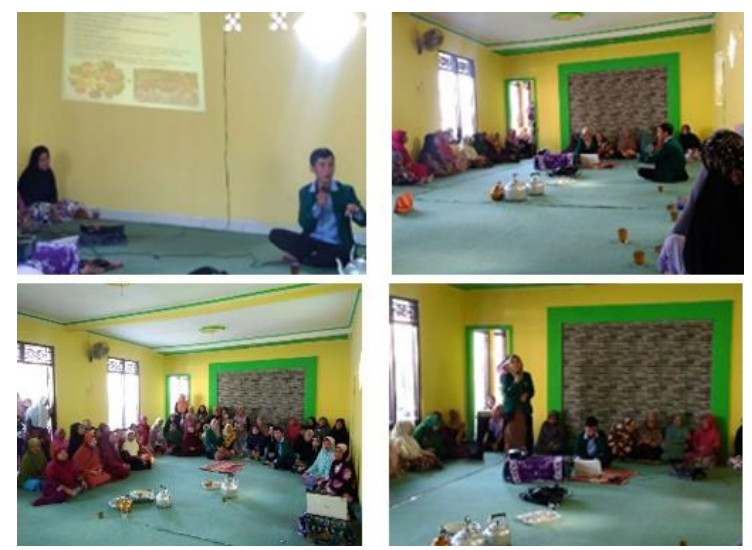

c. Penyuluhan hipertensi dan Gizi pada ibu-ibu pengajian Majlis Ta'lim AlMukhlisin. Kegiatan ini bertujuan agar ibu-ibu mengenal : arti hipertensi, gejala, penyebab, komplikasi, dan pencegahan hipertensi. Serta materi gizi yang memberikan informasi tentang sumber-sumber makanan yang mengandung gizi sehat dan juga memberikan pengarahan tentang pola hidup sehat.
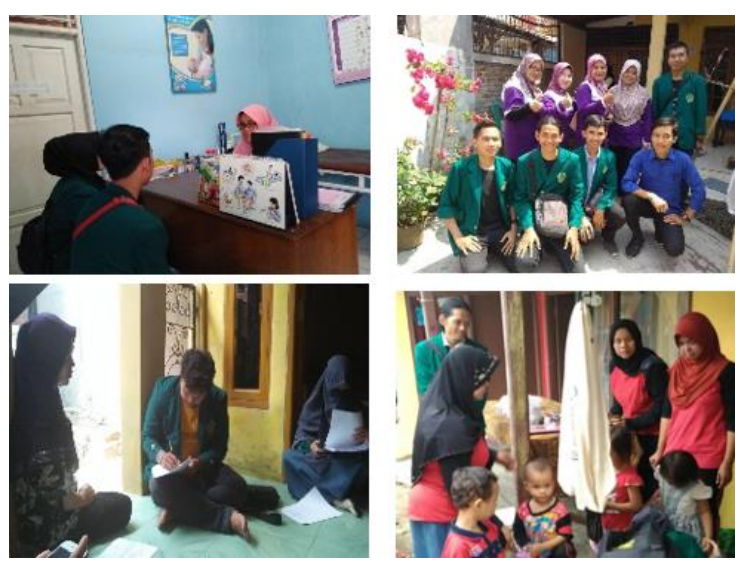

d. Pengambilan Data Kesehatan Ibu dan Anak. Kegiatan ini umtuk membantu pihak bidan Puskesmas Situ Udik.

\section{Program Bidang Agama}
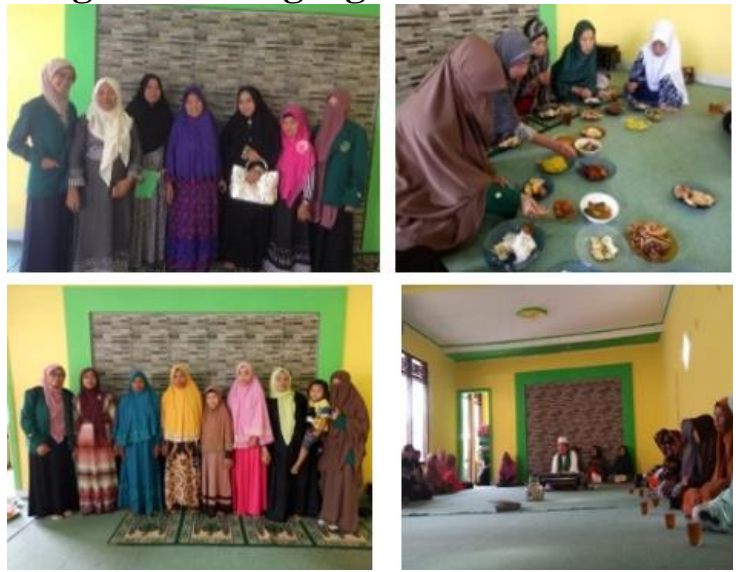

a. Menghadiri Majlis Ta'lim Al-Mukhlisin pada hari Jumat jm 08.00 sampai jam 10.00 yang dilanjutkan dengan agenda bacakan (makan-makan) bersama ibuibu.
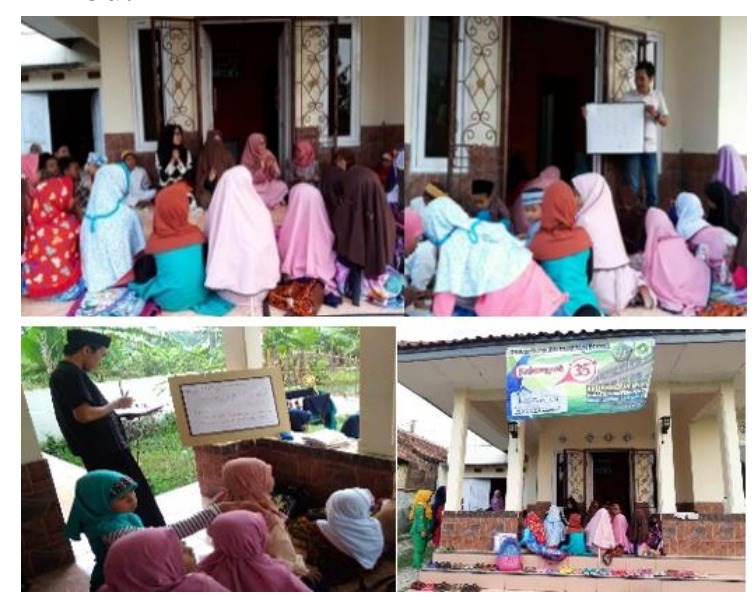

b. Taman Qur'an yang didalamnya membahas tentang pengajaran do'ado'a harian, hafalan Hadits sehari-hari, nama-nama surat beserta artinya. 

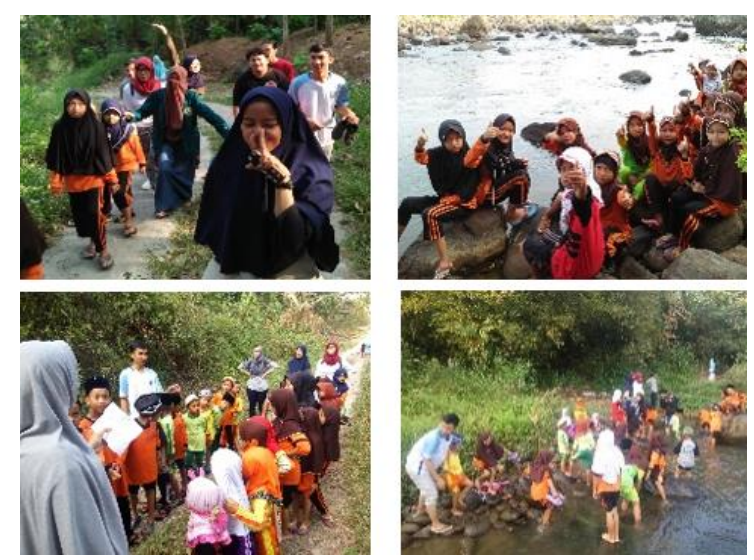

c. Senam Sehat dan Jalan Sehat anak-anak pada hari Minggu.
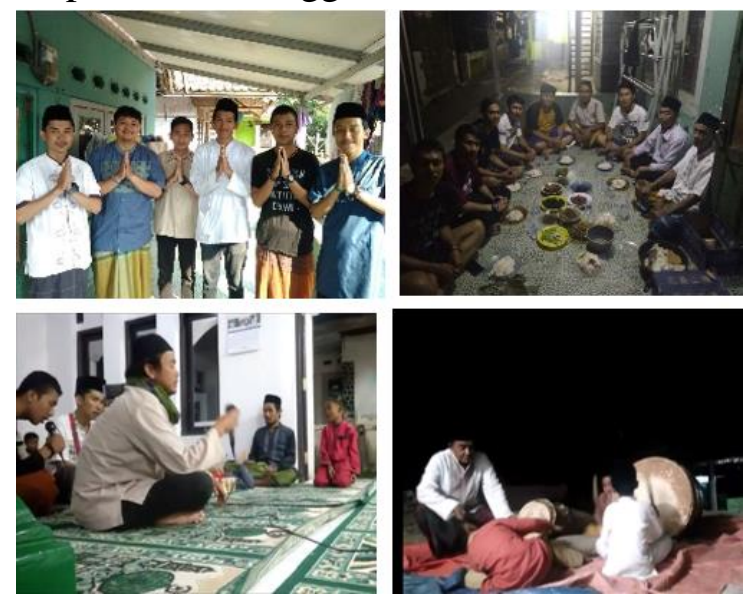

d. Menghadiri kegiatan Takbiran dan Sholat 'idul Adha di kampung Bubulak

\section{Program Bersama}
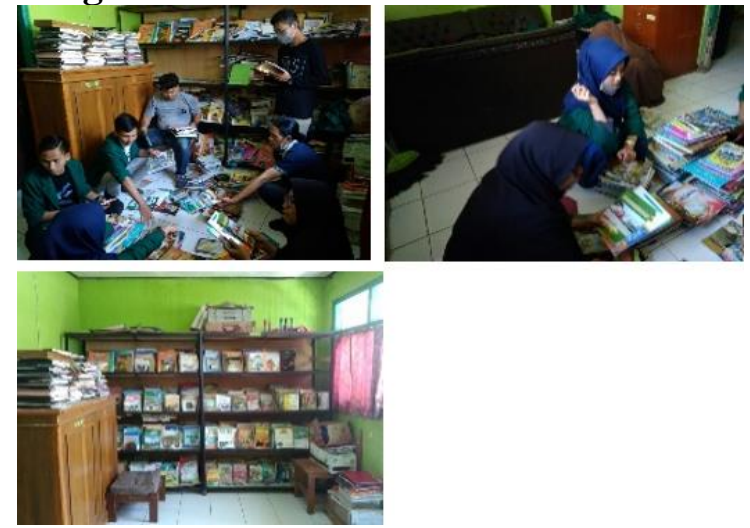

a. Menata Perpustakaan

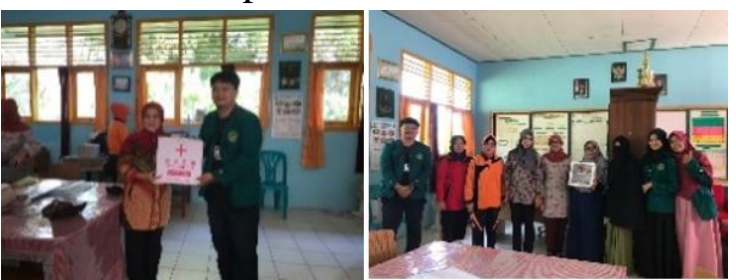

b. Membersihkan UKS dan Penyediaan alat P3K
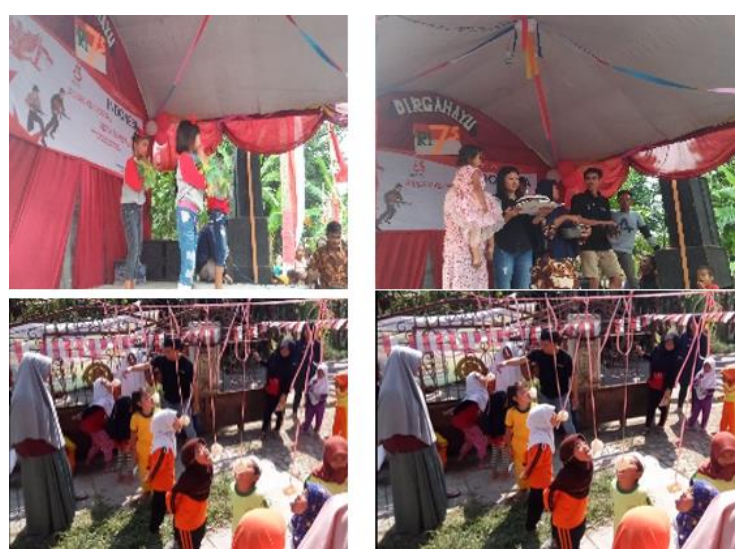

c. Kegiatan 17 Agustus ke 73

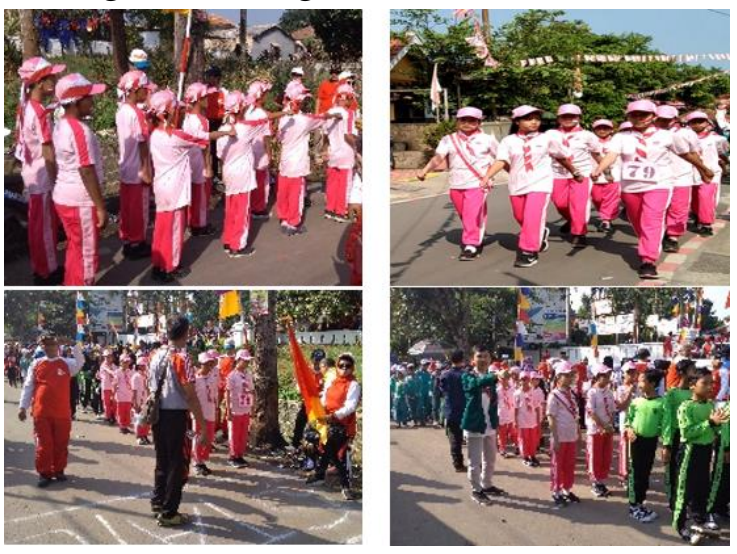

d. Gerak Jalan bersama anak SD

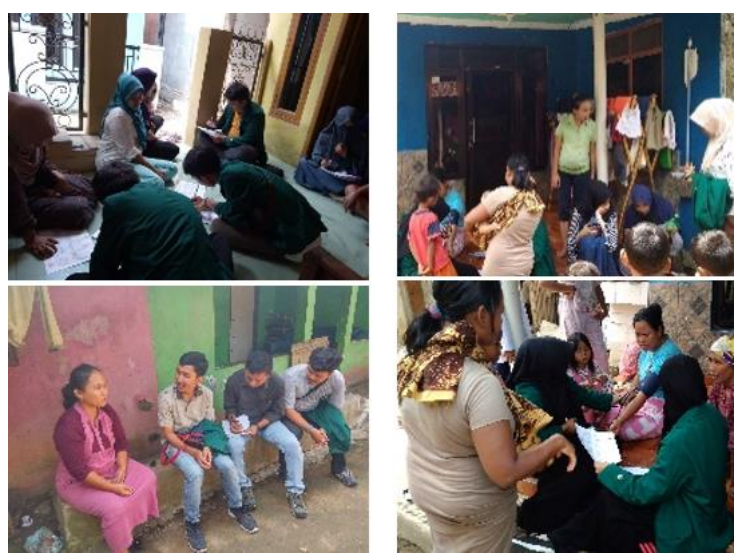

e. Pendataan Penduduk

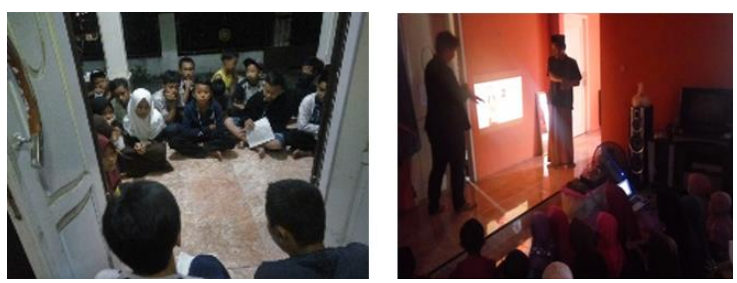

f. Nobar Film Kemerdekaan 


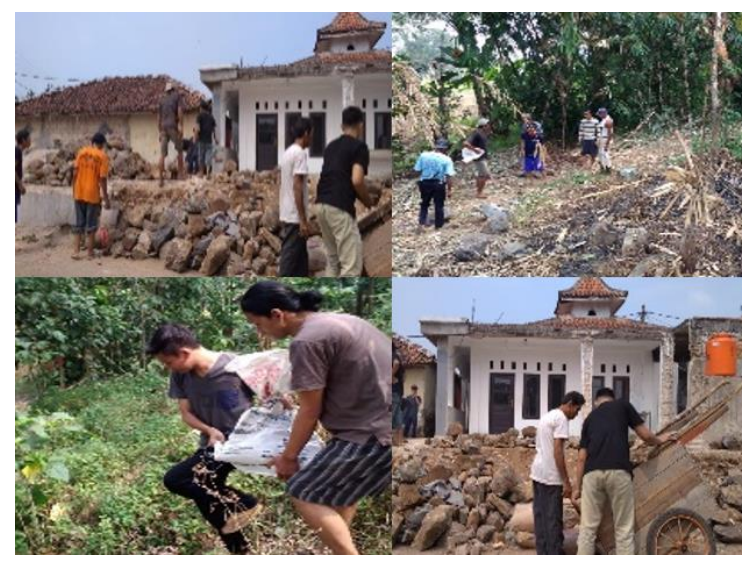

g. Kerja Bakti Renovasi Masjid

\section{KESIMPULAN}

1. Masyarakat Kp. Bubulak Rt 02 Rw 08 Desa Sukamaju sangat antusias dengan Program Kegiatan KKN kelompok 35 yang dijalankan.

2. Masyarakat Kp. Bubulak Rt $02 \mathrm{Rw} 08$ Desa Sukamaju sangat antusias dengan Program Pendidikan khususnya pada kegiatan bimbel pelajaran agama, bahasa inggris, komputer. Untuk membantu kualitas pendidikan anakanak.

\section{SARAN}

Dari hasil program yang telah dilaksanakan oleh masing-masing bidang, maka didapatkan informasi untuk dijadikan rekomendasi.

\section{a. Bidang Kesehatan}

Untuk desa agar lebih memperhatikan sarana kebersihan lingkungan, menyediakan tempat sampah di kampung bubulak yang memadai agar masyarakat membuang sampah pada tempatnya dan sarananya lebih terjangkau. Menyediakan posyandu khusus disetiap RW, lebih sering meberikan penyuluhan atau mengedukasi masyarakat agar lebih mengingat dan merealisasikan apa yang telah di informasikan.
3. Selain pada program pendidikan, masyarakat antusias pada bidang kesehatan dengan diadakan pengecekan tekanan darah.

4. Pada bidang-bidang lain pengadaan nomor rumah sebanyak 80 buah dan pembagian 1.250 pohon kepada masyarakat untuk menghijaukan kampung Bubulak.

\section{b. Bidang Pendidikan dan Bidang Agama}

Semoga aparatur pemerintahan bisa meningkatkan kualitas pendidikan dengan baik dimana sarana dan prasarana yang sangat penting di sekolah harus bisa di tingkatkan, dengan sarana yang baik akan meningkatkan kualitas SDM di sekolah dan membuat siswa nyaman berada di sekolah. Semoga juga pihak desa melihat kondisi sekitar sekolah karena jarak pembuangan sampah ke sekolah itu jaraknya tidak lumayan jauh.

\section{c. Bidang Ekonomi}

Perlu adanya peran desa dalam menyediakan UKM untuk menambah pengahasilan masyarakat kampung bubulak dan meningkatkan kreativitas perekonomian hasil dari pertanian. 


\section{d. Bidang Teknik}

Perlu adanya penerangan jalan menuju kampung bubulak serta pengadaan

\section{REFERENSI}

Administrasi Profil Desa Ciampea

Bahari (2010). Toleransi Beragama Mahasiswa (Studi tentang Pengaruh Kepribadian, Keterlibatan Organisasi, Hasil Belajar Pendidikan Agama, dan Lingkungan Pendidikan terhadap Toleransi Mahasiswa Berbeda Agama pada 7 Perguruan Tinggi Umum Negeri. Jakarta: Kementrian Agama RI Badan Litbang dan Diklat Puslitbang Kehidupan Keagamaan. kaca cembung di belokan jalan kampung Bubulak. serta peran sekolah seharusnya mengajarkan ilmu dasar tentang computer.

Gall, M.D., Gall, J.P. dan Borg,W.R. (2003). Educational Research an Introduction. Boston: Pearson Education, Inc.

Fahmi eroby, 2008, Pendidikan berbasis masyarakat. Yogyakarta

LPPM; Universitas Ibn Khaldun Bogor;. (2018). Petunjuk Pelaksanaan KKN Tematik Terintegrasi 2018. 